\title{
Variant Brain-Derived Neurotrophic Factor (BDNF) (Met66) Alters the Intracellular Trafficking and Activity-Dependent Secretion of Wild-Type BDNF in Neurosecretory Cells and Cortical Neurons
}

\author{
Zhe-Yu Chen, ${ }^{1,3}$ Paresh D. Patel, ${ }^{4}$ Gayatree Sant, ${ }^{1}$ Chui-Xiang Meng, ${ }^{5}$ Kenneth K. Teng, ${ }^{2}$ Barbara L. Hempstead, ${ }^{2}$ and \\ Francis S. Lee ${ }^{1}$ \\ ${ }^{1}$ Department of Psychiatry and Pharmacology and ${ }^{2}$ Division of Hematology, Department of Medicine, Weill Medical College of Cornell University, New \\ York, New York 10021, ${ }^{3}$ Department of Neurobiology, the Second Military Medical University, Shanghai 200433, China, ${ }^{4}$ Mental Health Research Institute \\ and Department of Psychiatry, The University of Michigan Medical School, Ann Arbor, Michigan 48109, and ${ }^{5}$ Department of Basic Medical Sciences, the \\ Second Military Medical University, Shanghai 200433, China
}

\begin{abstract}
Brain-derived neurotrophic factor (BDNF) plays a critical role in nervous system and cardiovascular development and function. Recently, a common single nucleotide polymorphism in the $b d n f$ gene, resulting in a valine to methionine substitution in the prodomain $\left(\mathrm{BDNF}_{\mathrm{Met}}\right)$, has been shown to lead to memory impairment and susceptibility to neuropsychiatric disorders in humans heterozygous for

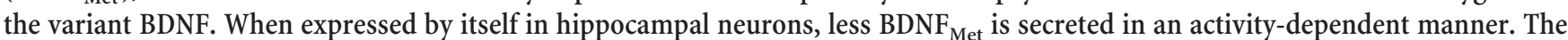
nature of the cellular defect when both $\mathrm{BDNF}_{\mathrm{Met}}$ and wild-type $\mathrm{BDNF}\left(\mathrm{BDNF}_{\mathrm{Val}}\right)$ are present in the same cell is not known. Given that this

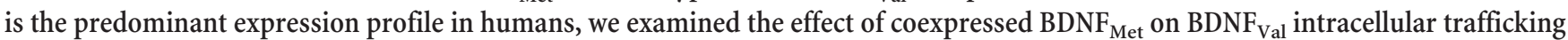
and processing. Our data indicate that abnormal trafficking of $\mathrm{BDNF}_{\mathrm{Met}}$ occurred only in neuronal and neurosecretory cells and that

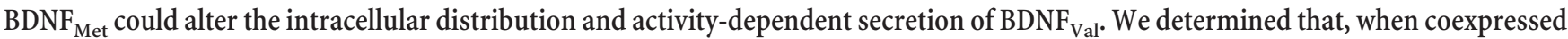
in the same cell, $\sim 70 \%$ of the variant $\mathrm{BDNF}$ forms $\mathrm{BDNF}_{\mathrm{Val}} \cdot \mathrm{BDNF}_{\mathrm{Met}}$ heterodimers, which are inefficiently sorted into secretory granules resulting in a quantitative decreased secretion. Finally, we determined the form of BDNF secreted in an activity-dependent manner and observed no differences in the forms of $\mathrm{BDNF}_{\mathrm{Met}}$ or the $\mathrm{BDNF}_{\mathrm{Val}} \cdot \mathrm{BDNF}_{\mathrm{Met}}$ heterodimer compared with $\mathrm{BDNF} \mathrm{Val}$. Together, these findings indicate that components of the regulated secretory machinery interacts specifically with a signal in the BDNF prodomain and that perturbations in BDNF trafficking may lead to selective impairment in CNS function.
\end{abstract}

Key words: brain derived neurotrophic factor; polymorphism; prodomain; proneurotrophin; intracellular trafficking; regulated secretion

\section{Introduction}

Brain-derived neurotrophic factor (BDNF) has been established to play critical roles in vertebrate nervous system and cardiovascular development and function (Tessarollo, 1998; Huang and Reichardt, 2001; Chao, 2003). Recently, a polymorphism in the $b d n f$ gene leading to a valine (Val) to methionine (Met) substitution at position 66 in the prodomain $\left(\mathrm{BDNF}_{\mathrm{Met}}\right)$ has been associated with increased susceptibility in humans heterozygous for

\footnotetext{
Received 0ct. 17, 2003; revised March 23, 2004; accepted March 23, 2004.

This work was supported by the DeWitt-Wallace Fund of the New York Community Trust (F.S.L.), the National Alliance for Research on Schizophrenia and Depression (F.S.L.), the Nancy Pritzker Depression Network (F.S.L., P.D.P.), Foundation for the Author of National Excellent Doctoral Dissertation of China Grant 200229 (Z.-Y.C.), Shanghai Youth Science and Technology Phosphor Grant 010B14001 (Z.-Y.C.), National Natural Science Foundation of China Grant 30000048 (Z.-Y.C.), and National Institute of Neurological Disorders and Stroke Grant NS30687 (B.L.H., K.K.T.). We thank Alessandro leraci for cortical neuronal cultures, Rosemary Kraemer for vascular smooth muscle cell cultures, and Margit Burmeister, Moses Chao, and Pilar Perez for helpful discussions.

Correspondence should be addressed to Francis S. Lee, Weill Medical College of Cornell University, 1300 York Avenue, Box 244, New York, NY 10021. E-mail: fslee@med.cornell.edu.

D01:10.1523/JNEUROSCI.0348-04.2004

Copyright $\odot 2004$ Society for Neuroscience $\quad$ 0270-6474/04/244401-11\$15.00/0
}

the polymorphism to neuropsychiatric disorders, including Alzheimer's disease (Ventriglia et al., 2002), Parkinson's disease (Momose et al., 2002), bipolar disorder (Neves-Pereira et al., 2002; Sklar et al., 2002), depression (Sen et al., 2003), eating disorder (Ribases et al., 2003), and obsessive compulsive disorder (Hall et al., 2003). In addition, humans heterozygous for $\mathrm{BDNF}_{\mathrm{Met}}$ were shown to have memory impairments (Egan et al., 2003; Hariri et al., 2003). This polymorphism represents the first association of an alteration in BDNF to clinical dysfunction. Less is known about the molecular mechanisms underlying altered BDNF functioning. In one study, when expressed by itself in hippocampal neurons, less $\mathrm{BDNF}_{\mathrm{Met}}$ is secreted in an activitydependent manner (Egan et al., 2003).

Trafficking of BDNF from the biosynthetic pathway is a complex, highly regulated process, the mechanisms of which remain unclear. In this context, several questions have yet to be addressed regarding the specificity of this effect of the Met substitution on BDNF trafficking. First, does this substitution mutation in BDNF produce a general or cell type-specific defect in trafficking of this neurotrophin (NT)? Currently, only the trafficking of BDNF $\mathrm{Met}_{\mathrm{Met}}$ 
in hippocampal neurons has been examined (Egan et al., 2003). Decreased expression of BDNF in the certain peripheral cell populations, such as endothelial and vascular smooth muscle cells, have significant developmental consequences, including vascular destabilization and intracardiac hemorrhage (Donovan et al., 2000). Second, does coexpression of the $\mathrm{BDNF}_{\mathrm{Met}}$ alter the trafficking or processing of the wild-type BDNF $\left(\mathrm{BDNF}_{\mathrm{Val}}\right)$ ? Previous studies have shown that coexpressing different neurotrophins in the same cell can alter the trafficking fate of one of the neurotrophins (Farhadi et al., 2000). It remains unclear the nature of the trafficking defect when both $\mathrm{BDNF}_{\mathrm{Met}}$ and $\mathrm{BDNF}_{\mathrm{Val}}$ are expressed in the same cell. This is relevant because it has been estimated that $20-30 \%$ of the human population is heterozygous for the Met polymorphism (Neves-Pereira et al., 2002; Egan et al., 2003; Hariri et al., 2003; Sen et al., 2003) in which the wild-type and variant BDNF are coexpressed equally. The major phenotype observed in humans, memory impairment, has been shown to be present in these subjects heterozygous for the Met polymorphism (Egan et al., 2003; Hariri et al., 2003).

To address these questions on the role of the Met polymorphism on BDNF trafficking, we conducted an analysis of the intracellular and extracellular fates of $\mathrm{BDNF}_{\mathrm{Met}}$ and $\mathrm{BDNF}_{\mathrm{Val}}$ in non-neuronal and neuronal cells that endogenously produce and secrete BDNF. We conclude that the BDNF polymorphism affects only trafficking in neuronal cells and determined that, when expressed together in the same cell, $\mathrm{BDNF}_{\mathrm{Met}}$ alters the trafficking of $\mathrm{BDNF}_{\mathrm{Val}}$ through the formation of heterodimers that are less efficiently sorted into the regulated secretory pathway.

\section{Materials and Methods}

Reagents and antibodies. Murine NGF was obtained from Harlan Bioproducts (Indianapolis, IN), and human recombinant BDNF was obtained from PeproTech (Rocky Hill, NJ). Anti-FLAG antibodies were obtained from Sigma (St. Louis, MO) (monoclonal, M2, and polyclonal), and anti-HA (hemagglutinin) antibodies were obtained from Covance (Princeton, NJ) (monoclonal, HA.11) and Sigma (polyclonal). Antisecretogranin II (SecII) antibodies were from Biodesign (Saco, ME). Anti-MAP2 (microtubule-associated protein 2) antibody was from Sigma, and anti-Taul antibody was from Chemicon (Temecula, CA). Polyclonal anti-proBDNF and anti-proNGF antibodies were generated as described previously (Beattie et al., 2002). $\epsilon$-Amino-caproic acid (EACA) was purchased from American Diagnostica (Stamford, CT). Fluorescent secondary antibodies were from Molecular Probes (Eugene, OR) and Jackson ImmunoResearch (West Grove, PA). The restriction enzymes were purchased from Fermentas (Hanover, MD), and Pfu Turbo DNA was from Stratagene (La Jolla, CA). All other compounds were from Sigma.

Plasmid constructs. The human BDNF and NGF cDNA were subcloned into pCDNA3.1hygro expression vector (Invitrogen, Carlsbad, CA) using HindIII and XhoI sites. The HA or FLAG epitope tag was added to the $3^{\prime}$ end of the BDNF or NGF CDNA by PCR method. Additionally, the residues RR near the $\mathrm{C}$ terminus of NGF were mutated to AA to eliminate a potential proteolytic cleavage site. The Val to Met mutation at position 66 was generated by means of two-step PCR. Using PCR-based mutagenesis, a silent NotI site was generated immediately after the signal peptide of human BDNF or human NGF to facilitate generating dual-epitopetagged HA-BDNF-FLAG and HA-NGF-FLAG constructs. The HA tag was inserted just after signal peptide of BDNF or NGF, and the FLAG tag was attached to the $\mathrm{C}$ terminal of BDNF or NGF. All of the constructs were confirmed by DNA sequence to exclude potential PCR-introduced mutations.

PC12 and COS-7 cell culture and immunoprecipitation and immunoblotting. PC12 (clone 615) cells, stably overexpressing TrkA receptors (Hempstead et al., 1992), were maintained in DMEM (Invitrogen) containing 10\% fetal bovine serum (Invitrogen), 5\% horse serum (Invitrogen), supplemented with $100 \mathrm{U} / \mathrm{ml}$ penicillin-streptomycin (Invitro- gen), and 2 mu glutamine plus $200 \mu \mathrm{g} / \mathrm{ml} \mathrm{G} 418$ (Invitrogen). COS-7 cells were maintained in DMEM containing 10\% fetal bovine serum, supplemented with $100 \mathrm{U} / \mathrm{ml}$ penicillin, $100 \mathrm{U} / \mathrm{ml}$ streptomycin, and $2 \mathrm{~mm}$ glutamine. Lipofectamine 2000 (Invitrogen) was used to transfect DNA in cells. Forty-eight hours after transfection, lysates or condition medium were collected and analyzed by Western blot as described previously (Lee and Chao, 2001). Briefly, for sequential immunoprecipitation experiments, lysates were collected and incubated with polyclonal HA antibody (Sigma), followed by incubation with protein A Sepharose beads (Sigma). The remaining lysates were collected and incubated with polyclonal FLAG antibody (Sigma). Western blots were performed by separating proteins via SDS-PAGE, transferring to a polyvinylidene difluoride membrane (Bio-Rad, Hercules, CA), and immunoblotting with HA.11 (Covance) or FLAG M2 antibody (Sigma). The immunoreactive protein bands were detected by enhanced chemiluminescence (Pierce, Rockford, IL). For densitometric analysis, immunoreactive bands were scanned and intensity quantitated using NIH Image (Scion, Frederick, MD).

Smooth muscle cell cultures. Temperature-sensitive mouse smooth muscle cells that were initially grown from aortic explants of a transgenic mouse line expressing a temperature-sensitive simian virus 40 (SV40) $\mathrm{T}$ antigen (Kraemer et al., 1999) were cultured in DMEM containing 10\% fetal calf serum supplemented with $100 \mathrm{U} / \mathrm{ml}$ penicillin, $100 \mathrm{U} / \mathrm{ml}$ streptomycin, and $2 \mathrm{~mm}$ glutamine at $33^{\circ} \mathrm{C}$, a temperature at which the $\mathrm{T}$ antigen is expressed. One day after transfecting the BDNF plasmids, using Lipofectamine 2000 (Invitrogen), the temperature was raised to $39.5^{\circ} \mathrm{C}$, a temperature at which the $\mathrm{T}$ antigen is degraded and the cells exhibit a more differentiated phenotype. All experiments were performed $48 \mathrm{hr}$ after transfection.

Endothelial cell culture. Immortalized endothelial cells containing an SV40 T antigen (Schweitzer et al., 1997) were cultured in DMEM containing $10 \%$ fetal calf serum supplemented with $100 \mathrm{U} / \mathrm{ml}$ penicillin, 100 $\mathrm{U} / \mathrm{ml}$ streptomycin, and $2 \mathrm{~mm}$ glutamine. Lipofectamine 2000 (Invitrogen) was used to transfect DNA in cells. All experiments were performed $48 \mathrm{hr}$ after transfection.

Cortical cell cultures. Dissociated primary cultures of cortical neurons from embryonic day 18 rats were prepared from timed-pregnant Sprague Dawley rats. Fetuses were removed under sterile conditions and kept in PBS on ice for microscopic dissection of the cerebral cortex. The meninges were removed, and the tissue was placed in Neurobasal media (Invitrogen). The tissue was briefly minced with fine forceps and then triturated with a fire-polished Pasteur pipette. Cells were counted and plated on culture wells coated with $0.01 \mathrm{mg} / \mathrm{ml}$ poly-D-lysine overnight in a Neurobasal media containing B27 supplement (Invitrogen) and L-glutamine (0.5 mM) (Invitrogen). Experiments were conducted $4 \mathrm{~d}$ after plating.

Immunocytochemical staining and fluorescence microscopy. PC12 (615) cells or cortical neurons were grown on glass coverslips (Corning, Corning, NY), coated with poly-L-lysine (Sigma), and transfected with epitope-tagged neurotrophin constructs. Forty eight hours after transfection, cells were fixed with a $4 \%$ paraformaldehyde solution in PBS and permeabilized with brief treatment with cold methanol ( $5 \mathrm{~min}$ ), followed by washing with PBS three times. Cells were blocked with $5 \%$ goat serum in PBS for $30 \mathrm{~min}$. Specimens were incubated with primary antibodies and then incubated with subtype-specific fluorescenated secondary antibodies. Stained PC12 specimens were examined by epifluorescence microscopy using a CoolSNAP CCD camera (PhotoMetrics, Huntington Beach, CA) mounted on a Nikon (Tokyo, Japan) TE2000 microscope equipped with a motorized $\mathrm{Z}$ drive and either a $100 \times, 1.4$ numerical aperture objective or $60 \times 1.4$ numerical aperture objective and standard FITC-Texas Red dichroic filter sets. Confocal fluorescence microscopy was performed on cortical neuron specimens using a Zeiss (Oberkochen, Germany) LSM510 microscope fitted with a Zeiss $63 \times$, 1.4 numerical aperture objective with standard filter sets and standard (one Airy disc) pinhole.

Quantitative analysis of fluorescent images. To quantitate the amount of staining of BDNF in different regions of PC12 cells or cortical neurons, $\sim 20$ cells were examined at random that were expressing the epitopetagged BDNF. For PC12 cells, a three-dimensional (3D) stack of images was obtained by the use of the $\mathrm{Z}$ drive mounted on a Nikon TE2000 
microscope. For cortical neurons, the entire 3D stack of the cell was imaged by confocal microscopy. For each 3D stack of images, the background was subtracted from each individual slice, and the stack of the images was reconstructed using the using the $3 \mathrm{D}$ reconstruction module in the MetaMorph software (Universal Imaging Corporation, West Chester, PA). Two regions were delineated within each cell to denote cell body and processes (see Fig. 4D). The integrated intensities for each region in all of the slices were summed. In the case of experiments in which two species of BDNF were cotransfected in the same cell, staining intensities of the $\mathrm{BDNF}_{\mathrm{Val}}$ species was quantitated in the same manner as for the single staining conditions. The results of four independent experiments were compiled, and SEM between these experiments is indicated by the error bars.

To quantitate the proportion of colocalization between BDNF and the secretory granule marker SecII, PC12 cells were examined by epifluorescence microscopy using appropriate filter sets to selectively detect Alexa488 (FLAG) and Cy3 (SecII). Optical slices were obtained by the use of the $\mathrm{Z}$ drive mounted on a Nikon TE2000 microscope, and the slice containing the maximal fluorescent intensity was chosen. For cortical neurons, multiple optical confocal images $(0.6 \mu \mathrm{m})$ were obtained across the $z$-axis, and the slice containing the maximal fluorescent intensity was chosen. Staining intensity for each fluor and the proportion of colocalization was quantitated using the colocalization module in the MetaMorph software (Universal Imaging Corporation). Approximately 20 cells were examined at random. The results of four independent experiments were compiled, and SEM between these experiments is indicated by the error bars.

ELISA. PC12 $(615)$ cells $\left(4.5 \times 10^{5}\right)$ were seeded to six-well plates. One day before transfection, cells were placed in differentiation media $(1.5 \%$ horse serum, $1 \%$ fetal bovine serum, and $50 \mathrm{ng} / \mathrm{ml} \mathrm{NGF).} \mathrm{Then,} 4 \mu \mathrm{g}$ of $\mathrm{BDNF}_{\mathrm{Val}}, 4 \mu \mathrm{g}$ of $\mathrm{BDNF}_{\mathrm{Met}}$, or $2 \mu \mathrm{g}$ of $\mathrm{BDNF}_{\mathrm{Val}}$ plus $2 \mu \mathrm{g}$ of $\mathrm{BDNF}_{\mathrm{Met}}$ construct were added per well. Forty eight hours after transfection, cells were washed three time with Krebs'-Ringer's-Henseleit (KRH) buffer with the following composition (in mM): $125 \mathrm{NaCl}, 4.8 \mathrm{KCl}, 2.6 \mathrm{CaCl}_{2}, 25$ HEPES, $1.2 \mathrm{MgSO}_{4}$, 5.6 glucose, 1 sodium ascorbate, and $1.2 \mathrm{KH}_{2} \mathrm{PO}_{4}$, adjusted to $\mathrm{pH} 7.4$ with $\mathrm{NaOH}$. The conditioned media were collected after a $2 \mathrm{hr}$ incubation at $37^{\circ} \mathrm{C}$ and used as a measure of constitutive secretion. To determine regulated secretion, cells were washed three times with $\mathrm{KRH}$ buffer, followed by a 10 min incubation at $37^{\circ} \mathrm{C}$ in stimulated media [KRH buffer with an increased $\mathrm{KCl}$ concentration (56 $\mathrm{mm}$ ) and decreased $\mathrm{NaCl}$ concentration $(75 \mathrm{~mm})]$. The BDNF protein concentrations in the respective media samples were determined using the BDNF Emax immunoassay system (Promega, Madison, WI) with recombinant BDNF as a standard. Standards and samples were performed in duplicates, and each group contained 12 independent samples. After collecting condition media, cells were fixed and immunostained to determine the transfection efficiency. Each sample had a consistent transfection efficiency of $\sim 30 \%$.

Analysis of secreted forms of BDNF. Differentiated PC12 (615) cells were transfected with $4 \mu \mathrm{g}$ of $\mathrm{BDNF}_{\mathrm{Val}}, 4 \mu \mathrm{g}$ of $\mathrm{BDNF}_{\mathrm{Met}}$, or $2 \mu \mathrm{g}$ of $\mathrm{BDNF}_{\mathrm{Val}}$ plus $2 \mu \mathrm{g}$ of BDNF $\mathrm{Met}_{\mathrm{Met}}$ constructs. Forty-eight hours after transfection, cells were washed three times with KRH buffer and preincubated for $20 \mathrm{~min}$ at $37^{\circ} \mathrm{C}$ in the absence or presence of EACA $(10 \mathrm{~mm})$, aprotinin $(10 \mu \mathrm{g} / \mathrm{ml})$, and $\alpha_{2}$-plasmin inhibitor $(100 \mathrm{nM})$. Cells were then incubated for $10 \mathrm{~min}$ at $37^{\circ} \mathrm{C}$ in stimulated $\mathrm{KRH}$ media containing an increased $\mathrm{KCl}$ concentration $(56 \mathrm{mM})$ and decreased $\mathrm{NaCl}$ concentration (75 mM). The immunoreactive protein bands were detected by enhanced chemiluminescence (Pierce).

\section{Results}

\section{Identification and imaging of pro forms of BDNF}

To visualize intracellular localization and trafficking of BDNF, we generated a series of epitope-tagged neurotrophin expression constructs bearing combinations of C- and/or N-terminal epitope tag sequences. Immunodetection of C- and N-terminal epitopes on the same BDNF molecule would allow for BDNF pro and mature forms to be imaged by immunofluorescent micros- copy. This system allows us to assess both processing and trafficking alterations produced by the Met substitution in the same cell.

Because it has already been observed that BDNF and NGF have different intracellular processing patterns (Mowla et al., 1999, 2001), we also made dual-epitope-tagged NGF constructs to compare with BDNF. By Western blot analysis of transfected COS-7 cell lysates, we initially confirmed that immunoblotting for the C-terminal epitope (FLAG) recognizes both species of neurotrophins (pro and mature) for BDNF and NGF, whereas the N-terminal epitope (HA) recognizes only the pro form (Fig. $1 A)$. Of note, no smaller bands $(<32 \mathrm{kDa})$ were detected with the $\mathrm{N}$-terminal-directed antibody, suggesting that N-terminal antibody only recognized the pro form of neurotrophin and that the cleaved prodomain was not detected. Western blot analysis of transfected PC12 cell lysates confirmed that immunoblotting for a C-terminal epitope (HA) on BDNF and NGF recognize both pro and mature forms (Fig. $1 B$ ). Antibodies against the mature domain of BDNF and NGF (Fig. $1 B$ ) produced similar results in recognizing both pro and mature forms (Fig. $1 B$ ).

To image the intracellular locations of pro and mature neurotrophins, we transfected PC12 cells with the dual-epitope-tagged neurotrophin constructs and stained for the C-terminal FLAG and N-terminal HA epitopes. We observed almost complete overlap of the $\mathrm{N}$ - and C-terminal epitope tag staining patterns for wild-type BDNF (Fig. 1C). By Western blot analysis of COS-7 and PC-12 cell lysates (Fig. $1 A, B$ ), the antibodies directed against the C-terminal epitope detect both pro and mature forms, whereas the N-terminal epitope antibodies detect only the pro form. The predominant overlapping immunostaining of both Cand $\mathrm{N}$-terminal epitopes suggests that the pro form of BDNF is the major intracellular form. To confirm that this staining pattern was for proBDNF, PC12 cells were stained with pro-specific antibodies for BDNF. Similar to the dual-epitope staining pattern, the majority of immunoreactivity for prodomain staining was found in punctate structures in the distal processes of the PC12 cells and overlapped with the C-terminal antibody staining (data not shown). In contrast, $\mathrm{N}$ - and C-terminal epitope immunostaining for NGF in PC12 cells displayed minimal overlap, except in a perinuclear compartment (Fig. 1D). These results are consistent with past biochemical studies demonstrating that the majority of NGF appears to be cleaved in the Golgi apparatus, whereas BDNF is more predominantly in the pro form in neuronal cells (Mowla et al., 1999). Thus, our dual-epitope-tagged neurotrophin staining system allowed for subcellular visualization of both pro and mature forms for BDNF and NGF.

\section{Processing and trafficking of $\mathrm{BDNF}_{\mathrm{Met}}$ in non-neuronal cells}

The single nucleotide polymorphism in the BDNF that leads to a valine to methionine substitution at position 66 has been shown to lead to impaired BDNF secretion in cultured primary hippocampal neurons (Egan et al., 2003). We wanted to use our fluorescent imaging system to examine the specificity underlying defective $\mathrm{BDNF}_{\mathrm{Met}}$ trafficking. Our first question focused on whether this defect in secretion was specific to neuronal cells. We chose to study non-neuronal cells that endogenously produce and secrete BDNF. Endothelial cells and vascular smooth muscle cells in the cardiovascular system secrete and use BDNF as an autocrine or local paracrine mediator of cardiovascular development, maintenance of intracardiac vessel stability, as well as response to vascular lesioning (Donovan et al., 1995, 2000; Wang et al., 2000). The amount of BDNF in the vasculature and heart are at levels comparable with the CNS (Scarisbrick et al., 1993; Donovan et al., 1995; Hiltunen et al., 1996). These peripheral cells 
A
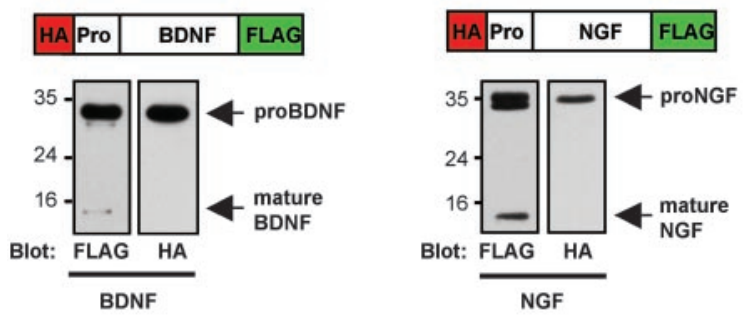

B
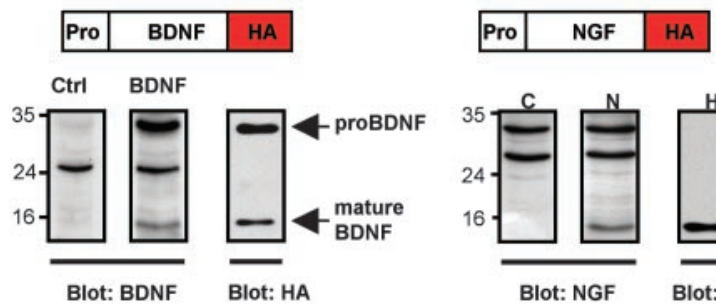

C

\section{\begin{tabular}{|l|l|l|l|}
\hline HA & Pro & BDNF & FLAG \\
\hline
\end{tabular}}

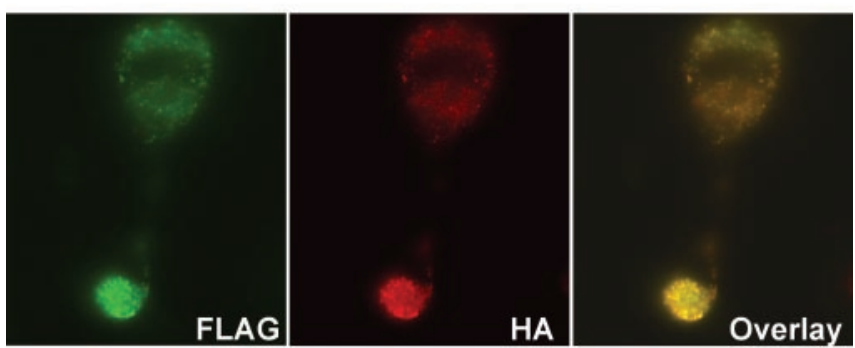

D
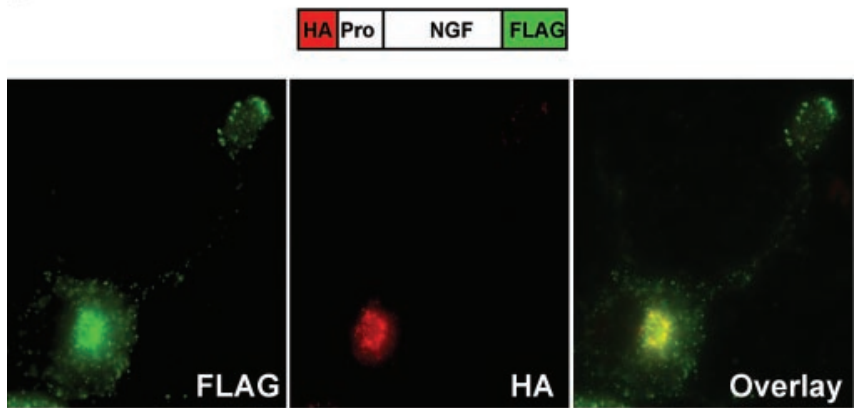

Figure 1. Processing and localization of epitope-tagged neurotrophins. A, Dual N-terminal HA-tagged and C-terminal FLAG-tagged BDNF or NGF was transfected into COS-7 cells, and, after $48 \mathrm{hr}$, lysates were prepared as described in Materials and Methods and analyzed by immunoblotting with anti-HA and anti-FLAG antibodies. B, Single C-terminal HA-tagged BDNF or NGF was transfected into differentiated PC12 cells. After $48 \mathrm{hr}$, lysates were prepared as described in Materials and Methods and analyzed by immunoblotting with C-terminal antibodies for BDNF or NGF or with anti-HA antibodies. Dual-epitope-tagged BDNF ( $C$ and NGF (D) were transfected in differentiated PC12 cells. After $48 \mathrm{hr}$, cells were fixed and permeabilized, and subcellular distribution of neurotrophins was visualized by indirect immunofluorescence microscopy using epitope antibodies. Representative epifluorescence images are shown.

differ from neurons in two important aspects. They lack the specialized depolarization-dependent secretion pathway, and they do not have a highly polarized morphology of neuronal cells.

In an endothelial cell line (Schweitzer et al., 1997), we observed a uniform distribution of wild-type and variant BDNF staining (Fig. 2A). In addition, for both wild-type and variant
A

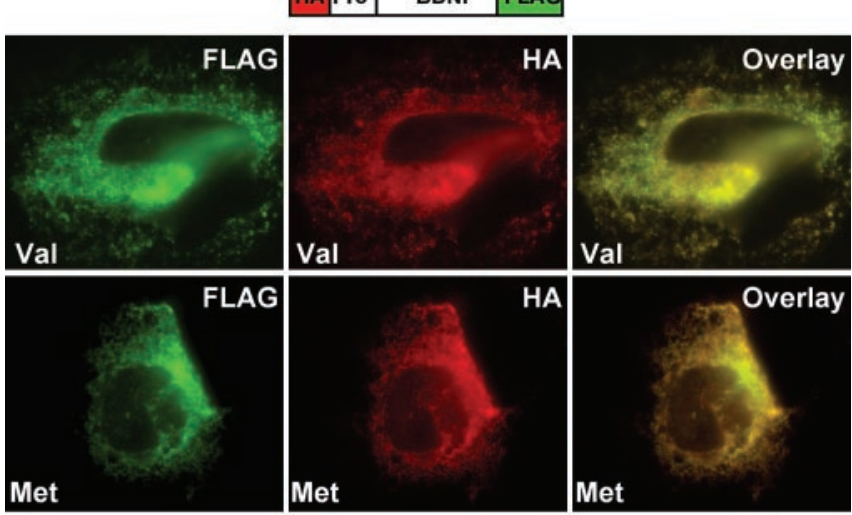

B
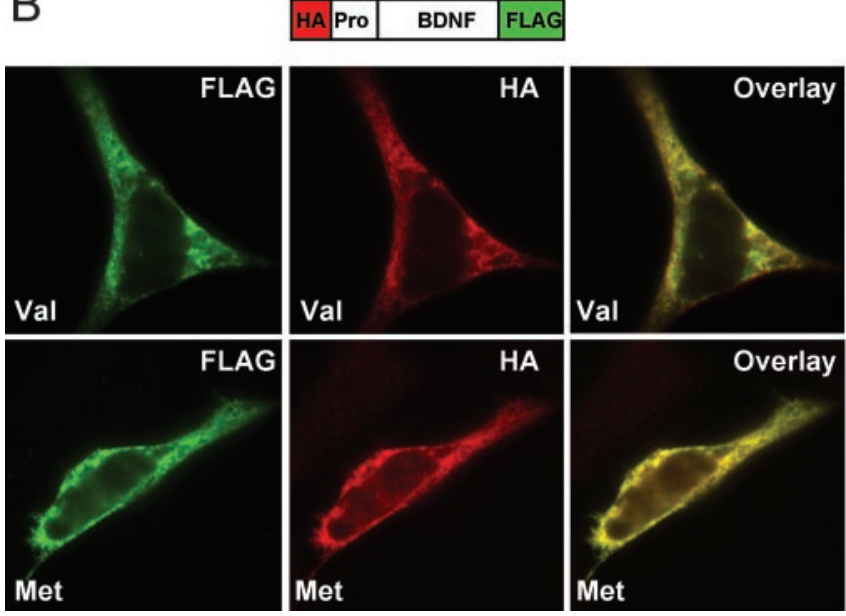

Figure 2. Variant BDNF has no defect in localization and secretion in endothelial and vascular smooth muscle cells. A, Localization of dual-epitope-tagged BDNF species in endothelial cells. After transfection, fixation, and permeabilization, subcellular distribution of wild-type (Val) and variant (Met) BDNF was visualized by indirect immunofluorescence microscopy using anti-HA and anti-FLAG antibodies. B, Localization of dual-epitope-tagged BDNF val $_{\text {in }}$ in vascular smooth muscle cells. After transfection, fixation, and permeabilization, subcellular distribution of $\mathrm{BDNF}_{\text {Val }}(\mathrm{Val})$ and variant (Met) BDNF was visualized by indirect immunofluorescence microscopy using anti-HA and anti-FLAG antibodies.

BDNF, there was almost complete overlap of the $\mathrm{N}$ - and C-terminal epitope tag staining patterns, suggesting that the predominant species was the pro form (Fig. $2 A$ ). Similarly, by immunostaining in an immortalized vascular smooth muscle cell line (Kraemer et al., 1999; Donovan et al., 2000), there was no difference in the distribution or the almost complete overlap of the $\mathrm{N}$ - and C-terminal epitope tag staining of transfected BDNF variant compared with wild-type BDNF (Fig. $2 \mathrm{~B}$ ). We also confirmed that staining for the N-terminal epitope antibody overlapped with staining with the proBDNF-specific antibody(data not shown). Furthermore, we measured by ELISA no functional difference between variant and wild-type BDNF secretion in these cells (data not shown). This is in marked contrast to BDN$\mathrm{F}_{\text {Met }}$ trafficking in hippocampal neurons (Egan et al., 2003) in which there has been shown to be defects in intracellular localization and regulated secretion. Together, these results suggest that, in cells that endogenously produce and secrete BDNF but lack the depolarization-dependent regulated secretory machinery, there is no apparent defect in processing, localization, or 
A

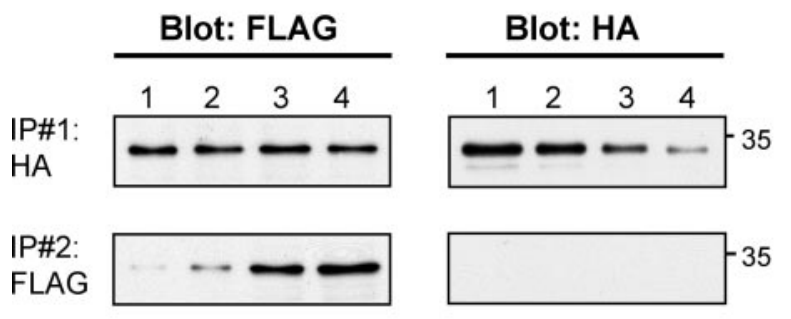

Lysate
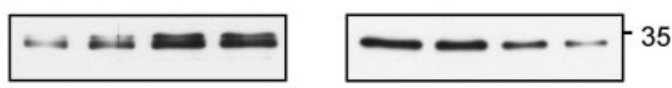

B
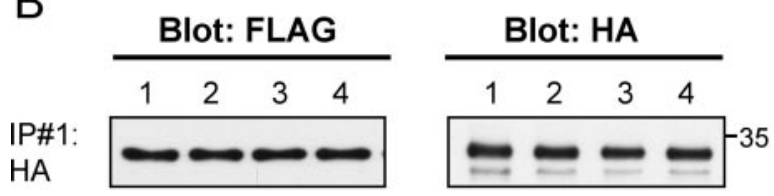

IP\#2: FLAG
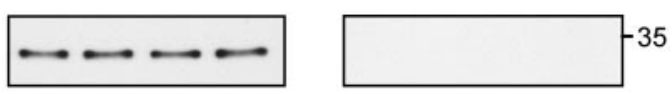

Lysate
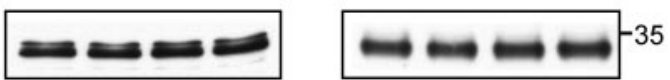

C

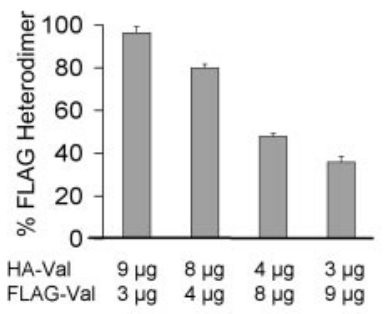

$\begin{array}{llll}1 & 2 & 3 & 4\end{array}$
D

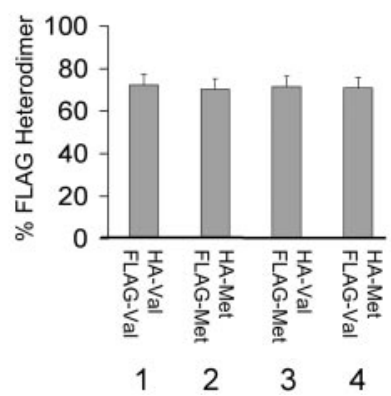

Figure 3. Coimmunoprecipitation of $B D N F_{V a l}$ and $B D N F_{M e t}$ heterodimers. $A$, To detect different degrees of heterodimerizatiom of two epitope-tagged forms of wild-type BDNF, COS-7 cells were transfected with two wild-type BDNF constructs bearing different C-terminal epitopes (HA or FLAG). The amount of cotransfected FLAG-BDNF and HA-BDNF was varied while maintaining a constant amount of total DNA $(12 \mu \mathrm{g})$ transfected. Cell lysates were prepared as described in Materials and Methods, and the first immunoprecipitations were performed with HA antibodies (IP\#1 indicates HA). A second immunoprecipitation was subsequently performed on the remaining lysates with FLAG antibodies (IP\#2 indicates FLAG), and immunoprecipitated samples were analyzed by Western blot. In addition, initial lysates ( $20 \mu \mathrm{g}$ of total protein) were analyzed by Western blot for levels of transfected FLAG-BDNF and HA-BDNF. B, To detect different degrees of heterodimerizatiom of epitope-tagged forms of wild-type and variant BDNF, COS-7 cells were transfected with combinations of $\mathrm{BDNF}_{\mathrm{Val}}$ and $\mathrm{BDNF}_{\mathrm{Met}}$ constructs bearing different C-terminal epitopes $\left(H A-B D N F_{\text {Val }}\right.$ plus FLAG-BDNF ${ }_{\text {Val }}, H A-B D N F_{\text {Met }}$ plus FLAGBDNF $_{\text {Met }}, H A-B D N F_{\text {Val }}$ plus FLAG-BDNF ${ }_{\text {Met }}$, or FLAG-BDNF Val $_{\text {al }}$ plus HA-BDNF Met $_{\text {et }}$ ). A constant amount $(6 \mu \mathrm{g})$ of each epitope-tagged BDNF species was transfected to maintain a constant amount of total DNA (12 $\mu \mathrm{g})$ transfected. Cell lysates were prepared as described in Materials and Methods, and sequential immunoprecipitations were performed (IP\#1 indicates HA; IP\#2 indicates FLAG), as described in $A$, and analyzed by Western blot. In addition, initial lysates ( 20 $\mu \mathrm{g}$ of total protein) were analyzed by Western blot for levels of transfected BDNF $\mathrm{Val}_{\text {al }}$ and BDN$\mathrm{F}_{\text {Met }}$. C, Quantitation of Western blots in $A$ as a proportion of FLAG-BDNF immunoreactivity found in IP\#1 over the total FLAG immunoreactivity obtained from both immunoprecipitation steps (IP\#1 and IP\#2, Blot: FLAG). Mean \pm SEM proportions were determined from analysis of

secretion of $\mathrm{BDNF}_{\mathrm{Met}}$. Thus, $\mathrm{BDNF}_{\mathrm{Met}}$ does not have a generalized defect in secretion but rather a defect in a specific cell population, neuronal cells.

\section{Dimerization and trafficking of coexpressed $\mathrm{BDNF}_{\mathrm{Val}}$ and BDNF $_{\text {Met }}$ in neuronal cells}

Because the biosynthetic trafficking pathway in neuronal cells appears to be the primary pathway affected by this polymorphism, the second question we focused on was the effect of expression of $\mathrm{BDNF}_{\mathrm{Met}}$ on $\mathrm{BDNF}_{\mathrm{Val}}$ trafficking and processing. Coexpression of the wild-type and variant BDNF would closely reflect the condition in human populations that are heterozygous for this polymorphism and for which a clinical phenotype in memory, as well susceptibility to neuropsychiatric disorders, has been observed (Egan et al., 2003; Hariri et al., 2003; Lu, 2003b). First, we hypothesized that, when coexpressed in the same cell, pro forms of $\mathrm{BDNF}_{\mathrm{Met}}$ and $\mathrm{BDNF}_{\mathrm{Val}}$ may heterodimerize, because it has been demonstrated that heterodimers of BDNF with other neurotrophins can be formed (Heymach and Shooter, 1995; Farhadi et al., 2000). To determine quantitatively, the relative proportion of $\mathrm{BDNF}_{\mathrm{Met}}$ and $\mathrm{BDNF}_{\mathrm{Val}}$ heterodimerization when both forms are expressed in the same cell, we performed a series of sequential coimmunoprecipitation experiments. We initially determined whether we could quantitatively detect different degrees of heterodimerizatiom of two epitope-tagged forms of wild-type BDNF. We coexpressed in COS-7 cells wild-type C-terminal FLAG-BDNF $F_{V a l}$ and $\mathrm{HA}-\mathrm{BDNF}_{\mathrm{Val}}$ with increasing proportion of FLAG-BDNF ${ }_{\mathrm{Val}}$ compared with $\mathrm{HA}-\mathrm{BDNF}_{\mathrm{Val}}$ and subjected the lysates to an initial HA antibody immunoprecipitation (IP\#1) and then a FLAG antibody immunoprecipitation (IP\#2). As a control, we determined that the first immunoprecipitation with HA antibodies (IP\#1) pulled down $>95 \%$ of all of the detectable HA-tagged BDNF in the cell lysate, by performing a second immunoprecipitation with HA antibodies and quantitating the resultant immunocomplex by Western blot analysis (data not shown). The relative degree of FLAG-BDNF $\mathrm{Val}^{\circ} \mathrm{HA}-$ $\mathrm{BDNF}_{\mathrm{Val}}$ complex formation was determined by quantitation of the proportion of FLAG-BDNF ${ }_{\mathrm{Val}}$ coimmunoprecipitated by HA antibodies (Fig. 3A, IP\#1, Blot: FLAG) compared with the total

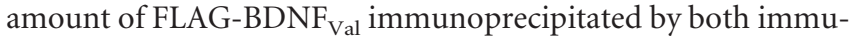
noprecipitation steps (Fig. 3A, IP\#1, IP\#2, Blot: FLAG). We confirmed that we could detect different proportions of epitopetagged BDNF heterodimers with this sequential coimmunoprecipitation procedure (Fig. $3 A, C$ ). Increasing the ratio of FLAGtagged BDNF compared with HA-tagged BDNF (FLAG/HA) from 1:3 to $3: 1$ led to a decrease in proportion of FLAGBDNF-HA-BDNF heterodimer formed from $96.5 \%$ to $36.1 \%$, respectively, with an concomitant increase in FLAG-BDNF homodimers (Fig. $3 A, C$ ).

We then coexpressed equal amounts of C-terminal FLAGBDNF $_{\mathrm{Met}}$ and HA-BDNF $\mathrm{Val}_{\mathrm{V}}$ in COS-7 cells and confirmed that, like wild-type BDNF, the predominant form in the cell lysates was the $32 \mathrm{kDa}$ pro form. Sequential coimmunoprecipitations were performed with HA antibodies (IP\#1) and then FLAG antibodies (IP\#2) (Fig. 3B, lane 3). We confirmed that the initial immunoprecipitation with $\mathrm{HA}$ antibodies was able to pull down all detect-

$\leftarrow$

three independent experiments. D, Quantitation of Western blots in $B$ as a proportion of FLAGBDNF immunoreactivity found in IP\#1 over the total FLAG immunoreactivity obtained from both immunoprecipitation steps (IP\#1 and IP\#2, Blot: FLAG). Mean \pm SEM proportions were determined from analysis of three independent experiments. 
able FLAG-BDNF $\mathrm{Met} \cdot \mathrm{HA}-\mathrm{BDNF}_{\mathrm{Val}}$ complexes (Fig. 3B). The relative degree of FLAG-BDNF ${ }_{\text {Met }} \cdot$ HA-BDNF Val $_{\text {complex }}$ formation was determined by quantitation of the proportion of FLAG-BDNF ${ }_{\mathrm{Met}}$ COimmunoprecipitated by $\mathrm{HA}$ antibodies compared with the total amount of FLAG$\mathrm{BDNF}_{\mathrm{Met}}$ immunoprecipitated by both immunoprecipitation steps. We determined that $71.5 \%$ of the $\mathrm{BDNF}_{\text {Met }}$ was complexed with $\mathrm{BDNF}_{\mathrm{Val}}$. This proportion was equivalent to the proportion of heterodimerization of coexpressed wildtype BDNF forms with different epitope tags (Fig. 3B, lane 1) or coexpressed variant BDNF forms with different epitope tags (Fig. 3B, lane 2). In addition, switching epitope tags on $\mathrm{BDNF}_{\mathrm{Met}}$ and $\mathrm{BDNF}_{\mathrm{Val}}$ did not alter this level of complex formation (Fig. 3B, lane 4). These experiments provide quantitative evidence that, when both $\mathrm{BDNF}_{\mathrm{Met}}$ and $\mathrm{BDNF}_{\mathrm{Val}}$ are coexpressed in the same cell, the majority of BDNF $_{\text {Met }}(>70 \%)$ is heterodimerized with $\mathrm{BDNF}_{\mathrm{Val}}$ (Fig. 3D).

Second, we determined whether there was a quantitative difference in intracellular distribution of coexpressed variant and wild-type BDNF in PC12 cells, an established neuronal cell line with a polarized morphology, and cortical neurons by use of the C-terminal epitope tag staining. We initially observed that, when expressed individually, BDNF ${ }_{\text {Met }}$ was localized more in the cell body compared with $\mathrm{BDNF}_{\mathrm{Val}}$ in both PC12 cells and cortical neurons (Fig. $4 A, C$ ). We then observed in PC12 cells (Fig. $4 B$ ) and cortical neurons (data not shown) that, when coexpressed, the majority of FLAG-BDNF${ }_{\text {Met }}$ staining overlapped with $\mathrm{HA}-\mathrm{BDNF}_{\mathrm{Val}}$ staining, with little FLAG- or HA-alone staining observed. Quantitative analysis of colocalization of $\mathrm{BDNF}_{\mathrm{Met}}$ and $\mathrm{BDNF}_{\mathrm{Val}}$ showed that $>70 \%$ of wild-type and variant BDNF colocalized in the same cell (data not shown). This high degree of colocalization was equivalent to that observed when we cotransfected two wild-type BDNF constructs with different epitope tags (HA and FLAG) (data not shown). This high degree of colocalization is also consistent with the high degree of heterodimerization of pro forms of $\mathrm{BDNF}_{\mathrm{Met}}$ and $\mathrm{BDNF}_{\mathrm{Val}}$ (Fig. $3 D$ ).

To determine whether coexpression of $\mathrm{BDNF}_{\text {Met }}$ with $\mathrm{BDNF}_{\text {Val }}$ altered $\mathrm{BDNF}_{\mathrm{Val}}$ trafficking, we transfected equal amounts of the respective DNA constructs, which produced equal levels of BDNF protein expression, by Western blot analysis (data not shown). With the use of two different C-terminal epitope tags on the two species of neurotrophin (FLAG-BDNF Met $_{\text {and }}$ and
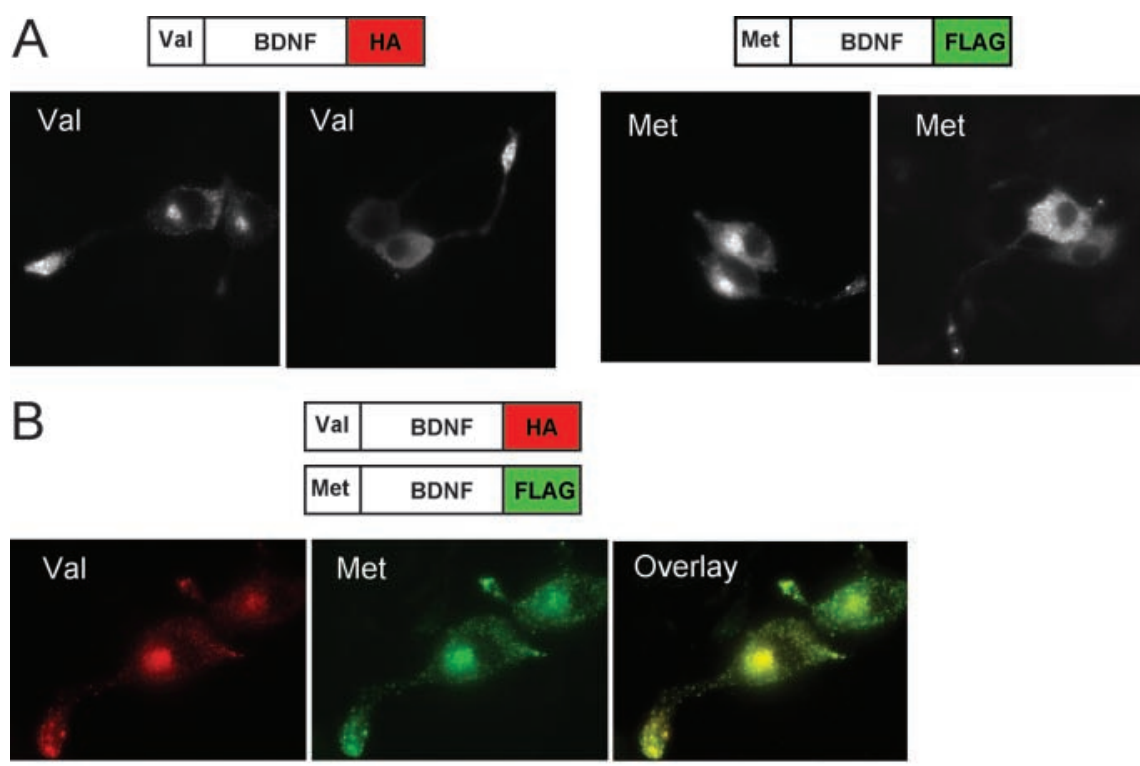

C
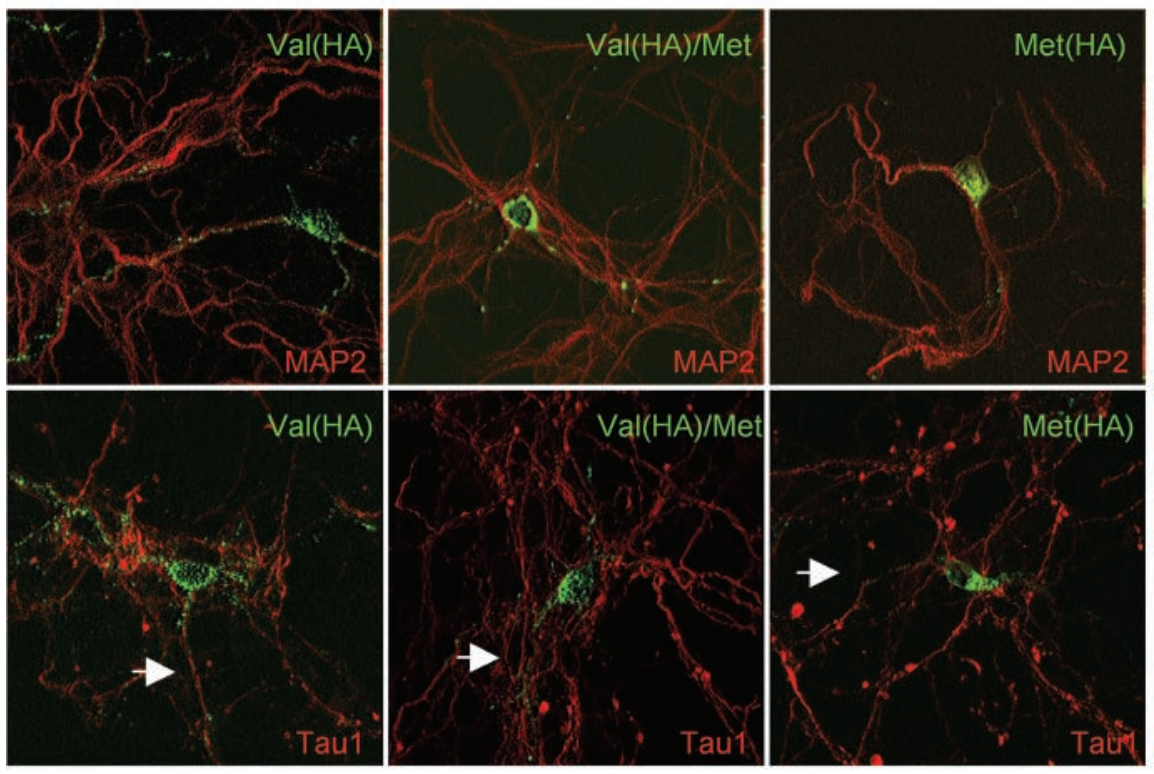

$\mathrm{D}$

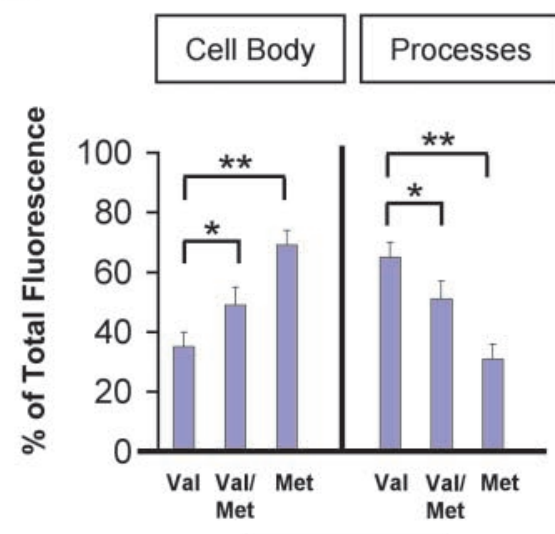

E

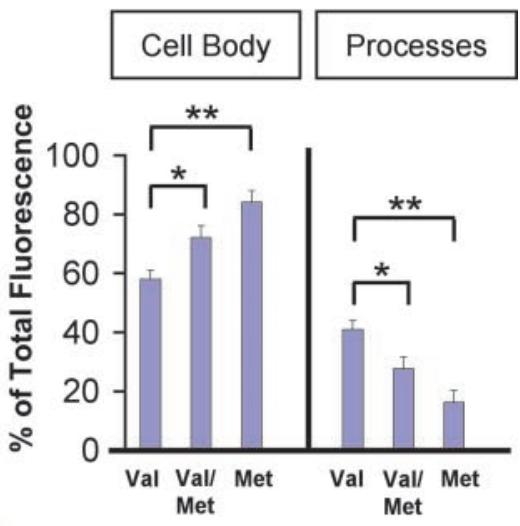

PC12 Cells

Cortical Neurons 
HA-BDNF $\mathrm{Val}_{\mathrm{Val}}$ ), we were able to follow the intracellular distributions of both wild-type and variant BDNF. In PC12 cells, we determined that, compared with wild-type BDNF transfection alone, cotransfection of both variant and wild-type BDNF leads to a significantly greater distribution of wild-type BDNF in the cell body $(p<0.01)$ (Fig. $4 B, D)$. In addition, in these cells coexpressing both wild-type and variant $\mathrm{BDNF}, \mathrm{BDNF}_{\mathrm{Met}}$ was also significantly localized in the cell body $(p<0.01$ ) (data not shown). In cortical neurons, we observed a similar shift in distribution for $\mathrm{BDNF}_{\mathrm{Val}}$ when coexpressed with $\mathrm{BDNF}_{\mathrm{Met}}$ (Fig. 4C). In these neurons, we quantitated the relative distribution of $\mathrm{BD}$ $\mathrm{NF}_{\mathrm{Val}}$ in the cell body and processes by $3 \mathrm{D}$ reconstruction of the entire neuron in $x, y$, and $z$ planes and determined that there was a significantly greater distribution of wild-type BDNF in the cell body compared with individually expressed $\mathrm{BDNF}_{\mathrm{Val}}(p<0.01)$ (Fig. $4 E$ ). In addition, in these cells coexpressing both wild-type and variant $\mathrm{BDNF}, \mathrm{BDNF}_{\mathrm{Met}}$ was also significantly distributed in the cell body $(p<0.01)$ (data not shown). For the cortical neuronal cultures, we also costained for neuronal markers of dendrites (MAP2) or axons (Tau1) to confirm their identity as neurons (Fig. 4C) and also noted no quantitative difference in selective distribution of the variant BDNF in dendrites or axons under any of the expression conditions (data not shown). These series of experiments suggested that $\mathrm{BDNF}_{\mathrm{Met}}$ can alter the trafficking of $\mathrm{BDNF}_{\mathrm{Val}}$ from the biosynthetic pathway leading to more concentrated distribution in the cell body of polarized neurosecretory cells.

\section{Identification of aberrant BDNF trafficking step involved in coexpressed $\mathrm{BDNF}_{\mathrm{Val}}$ and $\mathrm{BDNF}_{\mathrm{Met}}$}

It has been shown previously that, when expressed alone, BDN$\mathrm{F}_{\mathrm{Met}}$ has decreased distribution to distal neuronal processes, as well as decreased colocalization with secretory granule markers (Egan et al., 2003). In this context, the altered intracellular distribution of $\mathrm{BDNF}_{\mathrm{Val}}$ when coexpressed with $\mathrm{BDNF}_{\mathrm{Met}}$ could be attributable to two potential trafficking abnormalities: (1) a defect in sorting to the proper secretory organelle in transport to distal processes and/or (2) defect in transport to distal processes. To determine which step in the biosynthetic trafficking pathway led to the altered intracellular distribution of coexpressed BDN$\mathrm{F}_{\text {Val }}$, we first assessed colocalization with SecII, an established marker of secretory granules in the regulated secretory pathway (Huttner et al., 1991; Halban and Irminger, 1994; Ozawa and Takata, 1995). When $\mathrm{BDNF}_{\mathrm{Met}}$ and $\mathrm{BDNF}_{\mathrm{Val}}$ were cotransfected

\section{$\leftarrow$}

Figure 4. Processing and localization of variant and wild-type BDNF. A, Differentiated $\mathrm{PC} 12$ cells were transfected with $B D N F_{\text {Val }}$ (Val) or BDNF $_{\text {Met }}$ (Met) containing a C-terminal HA epitope or C-terminal FLAG epitope tag, respectively. Cells were fixed after 48 $\mathrm{hr}$ and permeabilized, and subcellular distribution of neurotrophins was visualized by indirect immunofluorescence microscopy, as described in Materials and Methods, using ant-HA or anti-FLAG antibodies. Representative epifluorescence images are shown. $B$, Differentiated $\mathrm{PC} 12$ cells were transfected with both $\mathrm{BDNF}_{\mathrm{Val}}$ containing a C-terminal $\mathrm{HA}$ epitope and $\mathrm{BDNF}_{\mathrm{Met}}$ containing a C-terminal FLAG epitope. Cells were fixed after $48 \mathrm{hr}$ and permeabilized, and subcellular distribution of neurotrophins was visualized by indirect immunofluorescence microscopy using epitope antibodies. Representative epifluorescence images are

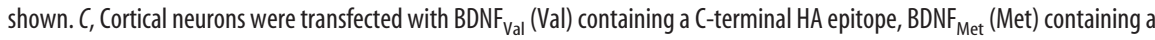
C-terminal FLAG epitope, or both BDNF $F_{\text {Val }}$ containing a C-terminal HA epitope and BDNF $_{\text {Met }}$ containing a C-terminal FLAG epitope (Val/Met). Cells were fixed after $48 \mathrm{hr}$ and permeabilized, and subcellular distribution of neurotrophins was visualized by confocal microscopy, as described in Materials and Methods, using epitope antibodies. In the case of the coexpressed BDNF ${ }_{\text {Val }}$ and BDNF Met $_{\text {, }}$ staining for the HA epitope was performed. In addition, all neurons were costained with either MAP2 or Tau1 to identify BDNF localization in dendrites and axons (white arrow), respectively. Representative reconstructed images are shown. D, Quantitative analysis of PC12 cell results illustrated in $B$, as described in Materials and Methods. The proportion of total fluorescence localized to the cell body or processes is presented as a mean \pm SEM determined from analysis of four independent experiments. $\left(^{*} p<\right.$ $0.01 ;{ }^{* *} p<0.001$; Student's $t$ test). E, Quantitative analysis of cortical neuron results illustrated in C, as described in Materials and Methods. The proportion of total fluorescence localized to the cell body or processes is presented as a mean \pm SEM determined from analysis of four independent experiments. $\left({ }^{*} p<0.01 ;{ }^{* *} p<0.001\right.$; Student's $t$ test). into differentiated PC12 cells or cortical neurons, less BDNF ed with the secretory granule marker (SecII) compared processes.

To control for the possibility that there was a defect in transin nonpolarized undifferentiated PC12 cells, which PC12 cells (Schubert and Klier, 1977), in the presence and absence of $\mathrm{BDNF}_{\mathrm{Met}}$. In undifferentiated $\mathrm{PC} 12$ cells, $\mathrm{BDNF}_{\mathrm{Val}}$ and $\mathrm{BNF}_{\mathrm{Met}}$ were in punctate structures and were evenly distributed with Secll staining $(p<0.001)$ (Fig. $5 C)$. When coexpressed, BDNF (data not shown) and $\mathrm{BDNF}_{\mathrm{V} \text { al }}$ also were observed to have a significantly decreased colocalization with Staining $(p<0.01)$ (Fig. $5 C$ ). These results suggest that the d Together, these results suggest that, when coexpressed, the resulting $\mathrm{BDNF}_{\mathrm{Met}}$ and $\mathrm{BDNF}_{\mathrm{Val}}$ complex is less efficiently sorted from the Golgi apparatus to secretory granules destined for the regu-

Functional consequences of aberrant intracellular trafficking on $\mathrm{BDNF}_{\text {Met }}$ secretion

To determine whether the altered colocalization of $\mathrm{BDNF}_{\mathrm{Val}}$, we BDNF constitutive orences, we assessed in PC12 cells whether BDNF ELISA assay, we observed first that BDNF $_{\text {Met }}$ (Met), transalone in differentiated or undifferentiated PC12 cells, has Don ${ }_{\text {Val }}(p<$ cells confirms our immunofluorescent results (Fig. 5C), suggesting that trafficking defect associated with the Met polymorphism is one attributable to inefficient sorting to secretory granules of total BDNF secreted in the regulated pathway was decreased compared with wild-type BDNF $(p<0.01)$ but higher than BDNF $_{\text {Met }}$ alone (Fig. $6 A, B$ ). There was no significant difference in constitutive secretion in either differentiated or undifferentiated PC12 cells (Fig. 6A,B). Together, these results suggest that the presence of a single phenocopy of $\mathrm{BDNF}_{\mathrm{Met}}$ is sufficient to impair wild-type BDNF regulated or activity-dependent secretion.

\section{Identification of secreted forms of $\mathrm{BDNF}_{\mathrm{Val}}$ and $\mathrm{BDNF}_{\text {Met }}$}

Our studies suggest that $\mathrm{BDNF}_{\mathrm{Val}}$. BDNF $_{\text {Met }}$ heterodimers are inefficiently sorted into the regulated secretory pathway and may be responsible for the observed clinical phenotypes. Because pro and mature forms of neurotrophins can induce opposing biological functions, apoptosis and survival, respectively (Lee et 
al., 2001; Beattie et al., 2002), it remains a possibility that an aberrant form of secreted BDNF heterodimer could also contribute to the observed biological effects. Thus, it was important to determine the actual forms of BDNF that are secreted in an activity-dependent manner. Although the forms of BDNF released constitutively from neuronal and neurosecretory cells has been observed previously (Mowla et al., 1999), it is not known what forms of BDNF are released from the regulated secretory pathway. We initially determined the specific forms of wild-type or variant BDNF that were secreted from PC12 cells when expressed alone after $\mathrm{KCl}$-induced depolarization. After a 10 min depolarization with $\mathrm{KCl}$, BDNF was harvested from the media of PC12 cells transfected with either a C- or N-terminal HA-tagged BDNF construct and immunoprecipitated with HA antibodies. First, we observed that there was a decrease in the amount of total $\mathrm{BDNF}$ released in the $\mathrm{BDNF}_{\mathrm{Met}}$ and $\mathrm{BDNF}_{\mathrm{Met}}$ plus $\mathrm{BDNF}_{\mathrm{Val}}$ conditions (Fig. 7A), consistent with the secretion results from the ELSA (Fig. 6). Then, we observed that, by immunoprecipitating a C-terminal HA-tagged BDNF, two forms of secreted BDNF were observed. These resolved as a major $19 \mathrm{kDa}$ and a minor 14 $\mathrm{kDa}$ form (Fig. 7A). No BDNF was observed after immunoprecipitating an N-terminal HA-tagged BDNF (Fig. 7B), suggesting that the 19 and $14 \mathrm{kDa}$ forms of $\mathrm{BDNF}_{\mathrm{Val}}$ and $\mathrm{BDNF}_{\text {Met }}$ lacked the $\mathrm{N}$-terminal epitope as a result of cleavage of the prodomain. During cotransfection of $\mathrm{HA}$ epitope-tagged $\mathrm{BDNF}_{\mathrm{Val}}$ and BDNF $_{\text {Met }}$ constructs in PC12 cells, the secreted forms of BDNF were identical to those of individually expressed $\mathrm{BDNF}_{\mathrm{Val}}$

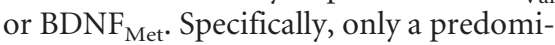
nant $19 \mathrm{kDa}$ and minor $14 \mathrm{kDa}$ form were detected by Western blot analysis during immunoprecipitation of the C-terminal HA-BDNF, and no BDNF forms were detected during immunoprecipitation of the $\mathrm{N}$-terminal HA-BDNF (Fig. $7 A, B$ ).

These results were unexpected because, by both Western bot analysis of PC12 lysates (Fig. $1 B$ ) and by immunofluorescent microscopy (Fig. 1C), the predominant intracellular form of BDNF was the uncleaved pro form containing intact $\mathrm{N}$-terminal and C-terminal epitope tags. To determine whether a rapid extracellular cleavage event was responsible for the generation of the lower molecular mass forms, similar secretion studies were performed in the presence of protease inhibitors. $\mathrm{BDNF}_{\mathrm{Val}}, \mathrm{BDNF}_{\mathrm{Met}}$, or $\mathrm{BDNF}_{\mathrm{Val}}$ and $\mathrm{BDNF}_{\text {Met }}$ were harvested, after a $10 \mathrm{~min}$
A
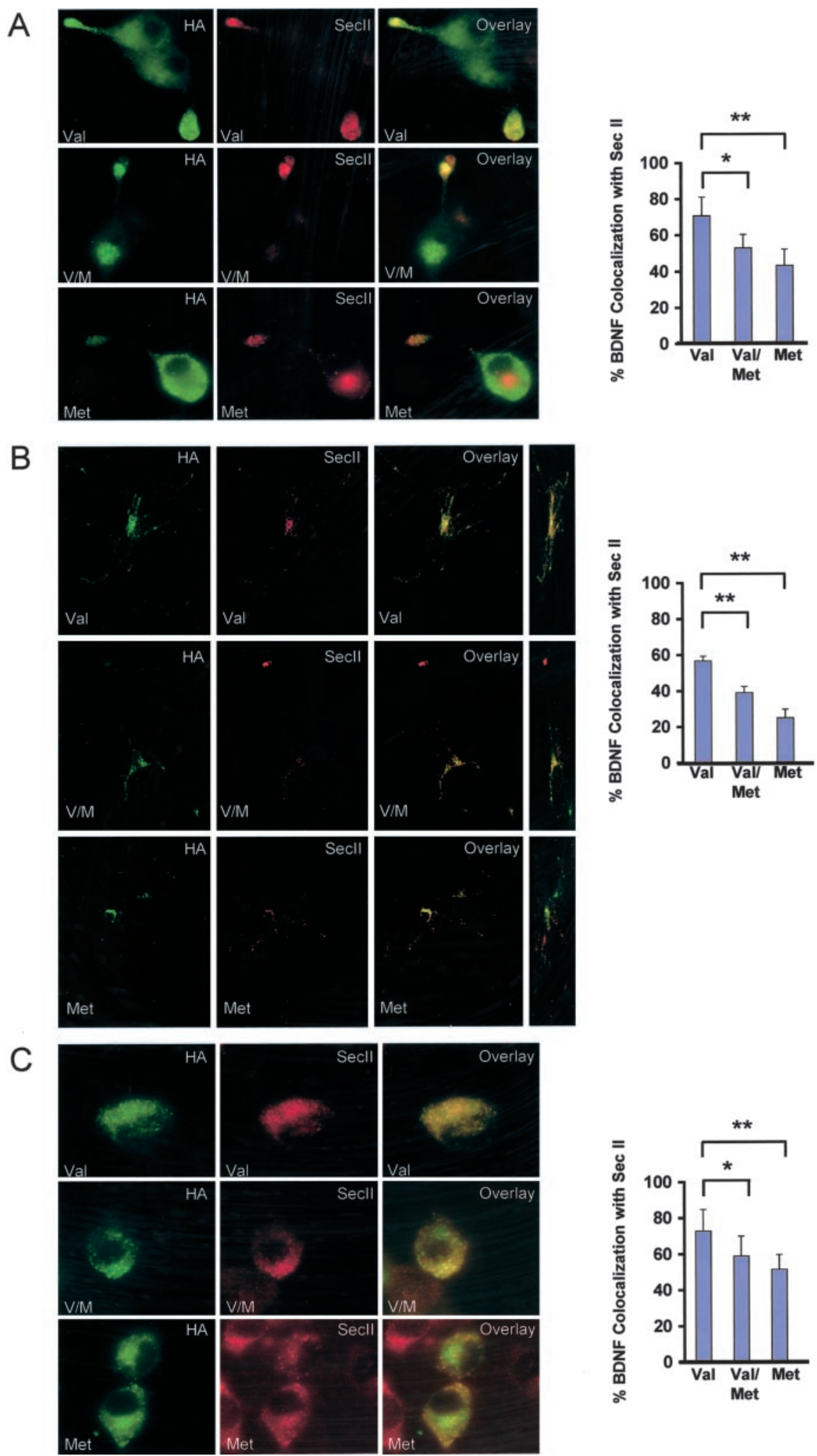

Figure 5. Subcellular colocalization of variant and wild-type BDNF with organelle markers. Differentiated $\mathrm{PC} 12$ cells $(A)$, cortical neurons $(B)$, and undifferentiated $\mathrm{PC} 12$ cells $(C)$ were transfected with C-terminal HA-tagged variant (Met), C-terminal HA-tagged wild-type BDNF (Val), or both C-terminal FLAG-tagged variant and HA-tagged wild-type BDNF (V/M). Cells were fixed after $48 \mathrm{hr}$ and permeabilized. Colocalization of BDNF and the secretory granule marker Secll was visualized by costaining with anti-HA and anti-Secll antibodies. Confocal three-dimensional reconstruction of serial $z$ planes were obtained, and alternate rotation angle is also shown for each representative cell. Quantitative analysis of results illustrated in $A-C$ was conducted by scoring $\sim 25$ cells for each BDNF condition. The proportion of colocalization between BDNF and Secll is presented as a mean \pm SEM determined from analysis of four independent experiments ( ${ }^{*} p<0.01 ;{ }^{* *} p<0.001$; Student's $t$ test). 
A

B
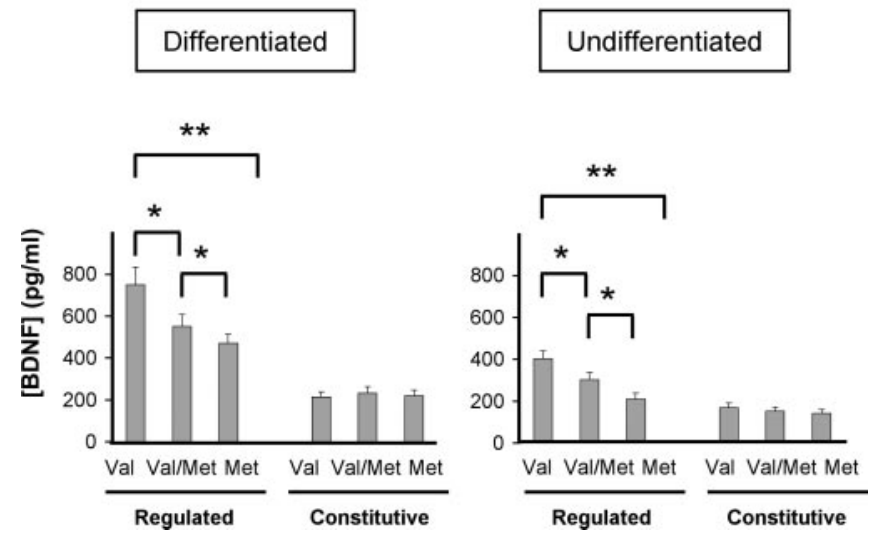

Figure 6. Regulated and constitutive secretion of $\mathrm{BDNF}_{\mathrm{Val}}$ and $\mathrm{BDNF}_{\mathrm{Met}}$. Differentiated $(A)$ and undifferentiated $(B) P C 12$ cells were transfected with $B_{D N F}\left(V_{\text {Val }}\left(V_{1}\right), B_{D N F}\right.$ Met $($ Met), or both BDNF species (Val/Met). After $48 \mathrm{hr}$, media was collected under depolarization and constitutive secretion conditions, as described in Materials and Methods, and analyzed by ELISA. Results are presented as a mean \pm SEM determined from analysis of three independent experiments $\left({ }^{*} p<0.01 ;{ }^{* *} p<0.001 ;\right.$ Student's $t$ test).

A

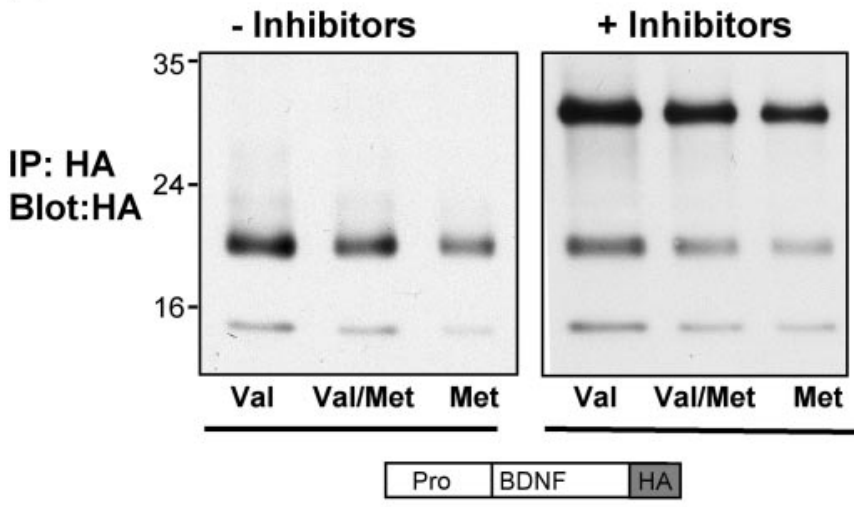

B

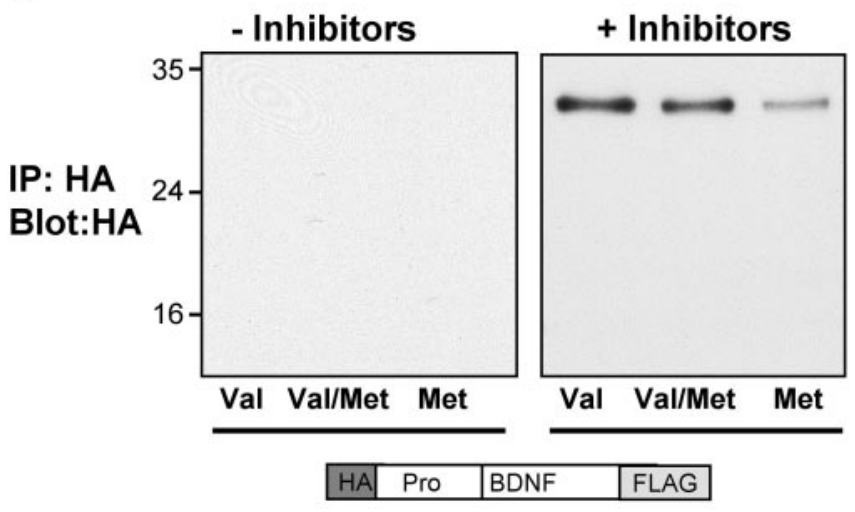

Figure 7. Identification of secreted forms of $\mathrm{BDNF}_{\mathrm{Met}}$. Differentiated $\mathrm{PC} 12$ cells were trans-

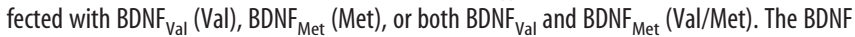
constructs contained either a single C-terminal HA epitope tag $(A)$ or dual N-terminal $\mathrm{HA}$ and FLAG C-terminal tags ( $B)$. After $48 \mathrm{hr}$, media was collected under depolarization conditions, as described in Materials and Methods, in the absence or presence of protease inhibitors. BDNF in the media was immunoprecipitated with polyclonal anti-HA antibodies and analyzed by immunoblotting with monoclonal anti-HA antibodies. Representative blots from three independent experiments are shown. depolarization with $\mathrm{KCl}$ in the presence of plasmin and metalloprotease inhibitors, from the media of PC12 cells, transfected with either a C-terminal or N-terminal HA-tagged BDNF construct. Western blot analysis of immunoprecipitates with HA antibodies revealed that the secreted forms of BDNF were predominantly the $32 \mathrm{kDa}$ form, with minor 19 and $14 \mathrm{kDa}$ forms (Fig. $7 A$ ). Parallel studies using a $\mathrm{BDNF}_{\mathrm{Val}}$ or $\mathrm{BDNF}_{\mathrm{Met}}$ construct, with an $\mathrm{N}$-terminal $\mathrm{HA}$ tag and C-terminal FLAG tag revealed only the higher $32 \mathrm{kDa}$ form (Fig. $7 B$ ), confirming that the full-length pro form of $\mathrm{BDNF}_{\mathrm{Val}}$ or $\mathrm{BDNF}_{\mathrm{Met}}$ is secreted during depolarization. The minimally higher migration pattern of the dual-epitope BDNF species is likely attributable to the presence of two epitope tags instead of one. In the presence of protease inhibitors, the secreted forms of coexpressed $\mathrm{BDNF}_{\mathrm{Val}}$ and $\mathrm{BDNF}_{\mathrm{Met}}$ were also identical to that of $\mathrm{BDNF}_{\mathrm{Val}}$, with the major form migrating at 32 $\mathrm{kDa}$ (Fig. $7 A, B$ ). Together, these results suggest that $\mathrm{BDNF}$ is secreted from the regulated secretory pathway as an intact proBDNF form, which then undergoes rapid cleavage during release. This result is consistent with previous studies demonstrating that constitutively secreted proBDNF is capable of being cleaved extracellularly by plasmin and metalloproteases (Lee et al., 2001). Importantly, the polymorphism at position 66 in the $\mathrm{BDNF}$ prodomain does not alter the relative proportion of pro and mature forms of BDNF secreted in an activity-dependent manner.

\section{Discussion}

Our present studies on the intracellular and extracellular fate of BDNF and a BDNF polymorphism, $\mathrm{BDNF}_{\mathrm{Met}}$, provide several new insights into the trafficking defect associated with this BDNF polymorphism. First, through immunofluorescent microscopy and secretion studies, we observed that this prodomain alteration impairs intracellular trafficking and regulated secretion of BDNF in primary cortical neurons and neurosecretory cells but not in endothelial and vascular smooth muscle cells. This finding is significant, because it suggests that the BDNF-producing neuronal cell populations in the CNS, but not those in the cardiovascular system, are specifically affected by this Met substitution in the BDNF prodomain. This finding is consistent with the functional deficits associated with the BDNF polymorphism in human subjects. The $\mathrm{BDNF}_{\text {Met }}$ polymorphism is relatively common in the human population with a prevalence for heterozygotes between 20 and $30 \%$ and the prevalence for the homozygotes at $\sim 4 \%$ (Neves-Pereira et al., 2002; Egan et al., 2003; Hariri et al., 2003; Sen et al., 2003). To date, several genetic linkage and behavioral studies have shown that this polymorphism has been associated with only neuropsychiatric disorders and memory impairments (Momose et al., 2002; Neves-Pereira et al., 2002; Sklar et al., 2002; Ventriglia et al., 2002; Egan et al., 2003; Hall et al., 2003; Hariri et al., 2003; Ribases et al., 2003; Sen et al., 2003). It is notable that no cardiovascular system impairments have been reported. BDNF has been established to play a significant role in heart development and postnatal cardiovascular system function. Deficient levels of BDNF in the cardiovascular system lead to vascular destabilization and intracardiac hemorrhage (Donovan et al., 1995, 2000; Kraemer et al., 1999; Wang et al., 2000). Our studies provide a plausible explanation for a mutation in BDNF causing a CNS phenotype but no obvious phenotypic defect in the cardiovascular system. The Met substitution in the prodomain leads to a selective impairment in regulated BDNF secretion, which is the primary means of BDNF release from neuronal cells but not from vascular cells.

A second finding from these studies is that the intracellular 
trafficking fate, as well as regulated secretion, of wild-type BDNF is altered by coexpression with the variant BDNF. From sequential coimmunoprecipitation studies, we demonstrate that, when coexpressed, $>70 \%$ of $\mathrm{BDNF}_{\mathrm{Met}}$ is in $\mathrm{BDNF}_{\mathrm{Val}} \cdot \mathrm{BDNF}_{\mathrm{Met}}$ heterodimers (Fig. $3 D$ ). This finding is consistent with previous studies that showed that coexpressing different neurotrophins can lead to the formation of heterodimers and that their trafficking fates can be altered (Heymach and Shooter, 1995; Farhadi et al., 2000; Hibbert et al., 2003). Although it has been assumed that BDNF does not form heterodimers in vivo with the other neurotrophins (NGF, NT-3, and NT-4), it is known that humans heterozygous for the $\mathrm{BDNF}_{\mathrm{Met}}$ polymorphism do coexpress both $\mathrm{BDNF}_{\mathrm{Val}}$ and $\mathrm{BDNF}_{\mathrm{Met}}$. Our coexpression studies are consistent with the functional studies from human subjects heterozygous for this polymorphism, in which having one copy of the $b d n f_{\text {Met }}$ gene led to deficits in cognitive tasks (Egan et al., 2003; Hariri et al., 2003). Thus, our studies provide insight into how the presence of one copy of the $\mathrm{BDNF}_{\text {Met }}$ gene can lead to a decrease in the amount of total BDNF released from cells in an activitydependent manner. Through the predominant formation of $\mathrm{BDNF}_{\mathrm{Val}} \cdot \mathrm{BDNF}_{\mathrm{Met}}$ heterodimers, there is less efficient BDNF trafficking into the regulated secretory pathway in neurons. This decreased regulated secretion of BDNF may explain the behavioral deficits observed in humans heterozygous for the relatively common Met polymorphism.

Third, we determined the form of BDNF secreted in an activity-dependent manner to be the $32 \mathrm{kDa}$ pro form that is rapidly cleaved to mature form after secretion (Fig. 7). It has been shown previously that proBDNF can be constitutively secreted from cultured neurons (Heymach et al., 1996; Mowla et al., 1999, 2001; Farhadi et al., 2000) and endothelial cells (Lee et al., 2001). However, it has also been established that the majority of BDNF released from neurons is attributable to activity-dependent secretion from the regulated secretory pathway rather than the constitutive secretory pathway ( $\mathrm{Lu}, 2003 \mathrm{~b})$. Our findings provide, for the first time, evidence that the $32 \mathrm{kDa}$ pro form of $\mathrm{BDNF}$ is the major form released from the regulated secretory pathway. This is significant because many biological functions mediated by BDNF in the nervous system are from BDNF released in this activitydependent manner. In particular, there is accumulating evidence that activity-dependent release of BDNF rapidly modulates synaptic transmission and neural plasticity in a variety of different experimental paradigms (Poo, 2001; Lu, 2003a). BDNF causes increases in EPSCs in hippocampal neurons (Kang and Schuman, 1995; Levine et al., 1995, 1996). The maintenance of long-term potentiation, the hallmark cellular basis for learning and memory, in the CA1 region of the hippocampus is also impaired in slices from mice deficient in BDNF (Korte et al., 1995). In addition, proneurotrophins such as proNGF has been shown to have biological activity through their selective activation of the p75 neurotrophin receptors (Lee et al., 2001; Beattie et al., 2002), whereas the mature forms interact selectively with Trk neurotrophin receptors. Our studies suggest that a significant proportion of the processing of proBDNF to mature BDNF may occur extracellularly. Thus, proteases on the cell surface or extracellular space will play a critical role in determining the proportion of BDNF forms (pro or mature) produced and thus the biological activity of BDNF that is released after depolarization.

In this context, we observed that the forms of $\mathrm{BDNF}_{\mathrm{Met}}$ released after depolarization, whether expressed alone or with $\mathrm{BDNF}_{\mathrm{Val}}$, did not differ from wild-type BDNF. We determined that there was no difference in proportions of pro and mature forms of $\mathrm{BDNF}_{\mathrm{Met}}$ released compared with $\mathrm{BDNF}_{\mathrm{Val}}$ (Fig. 7). We assume that the $19 \mathrm{kDa}$ form of BDNF, produced after cleavage of the $32 \mathrm{kDa}$ form, is attributable to cleavage occurring $\sim 80$ amino acids from the $\mathrm{N}$ terminus, which would remove the portion containing the Met polymorphism. Thus, the molecular mechanism underlying defective $\mathrm{BDNF}_{\mathrm{Met}}$ function appears to be attributable not to the form of BDNF secreted but more simply the amount of BDNF released in an activity-dependent manner.

These findings demonstrating altered intracellular trafficking of wild-type BDNF trafficking, with coexpression of the variant $\mathrm{BDNF}$, as well as the lack of proteolytic processing defects for the secreted $\mathrm{BDNF}_{\mathrm{Val}} \cdot \mathrm{BDNF}_{\mathrm{Met}}$ heterodimers, provide a more specific mechanistic framework to understand the secretion defect caused by the Met substitution. Our findings point to the presence of a specific trafficking signal in the BDNF prodomain region containing the Met substitution that is required for efficient BDNF sorting to the regulated secretory pathway. Importantly, through the formation of heterodimers with the wild-type BDNF, BDNF ${ }_{\text {Met }}$ is capable of altering the trafficking fate when both wild-type and variant BDNF are present in the same cell. These findings emphasize the importance of intracellular sorting of pro forms of BDNF into the cell-specific secretory pathways as a general mechanism of regulating appropriate biological activity. Thus, defects in the fidelity of these sorting events may lead to vulnerability to a wide range of CNS dysfunctions. An important direction for future studies will be to link the cell biological defect in $\mathrm{BDNF}_{\mathrm{Met}}$ trafficking to in vivo functional deficits found in human heterozygous for this polymorphism.

\section{References}

Beattie MS, Harrington AW, Lee R, Kim JY, Boyce SL, Longo FM, Bresnahan JC, Hempstead BL, Yoon SO (2002) ProNGF induces p75-mediated death of oligodendrocytes following spinal cord injury. Neuron 36:375-386.

Chao MV (2003) Neurotrophins and their receptors: a convergence point for many signalling pathways. Nat Rev Neurosci 4:299-309.

Donovan M, Miranda R, Kraemer R, McCaffrey T, Tessarollo L, Mahadeo D, Sharif S, Kaplan D, Tsoulfas P, Parada L, Hempstead B (1995) Neurotrophin and neurotrophin receptors in vascular smooth muscle cells. Regulation of expression in response to injury. Am J Pathol 147:309-324.

Donovan M, Lin M, Wiegn P, Ringstedt T, Kraemer R, Hahn R, Wang S, Ibanez C, Rafii S, Hempstead B (2000) Brain derived neurotrophic factor is an endothelial cell survival factor required for intramyocardial vessel stabilization. Development 127:4531-4540.

Egan M, Kojima M, Callicott J, Goldberg T, Kolachana B, Bertolino A, Zaitsev E, Gold B, Goldman D, Dean M, Lu B, Weinberger D (2003) The BDNF val66met polymorphism affects activity-dependent secretion of BDNF and human memory and hippocampal function. Cell 112:257-269.

Farhadi H, Mowla S, Petrecca K, Morris S, Seidah N, Murphy R (2000) Neurotrophin-3 sorts to the constitutive secretory pathway of hippocampal neurons and is diverted to the regulated secretory pathway by coexpression with brain-derived neurotrophic factor. J Neurosci 20:4059-4068.

Halban PA, Irminger JC (1994) Sorting and processing of secretory proteins. Biochem J 299:1-18.

Hall D, Dhilla A, Charalambous A, Gogos JA, Karayiorgou M (2003) Sequence variants of the brain-derived neurotrophic factor (BDNF) gene are strongly associated with obsessive-compulsive disorder. Am J Hum Genet 73:370-376.

Hariri AR, Goldberg TE, Mattay VS, Kolachana BS, Callicott JH, Egan MF, Weinberger DR (2003) Brain-derived neurotrophic factor val66met polymorphism affects human memory-related hippocampal activity and predicts memory performance. J Neurosci 23:6690-6694.

Hempstead BL, Rabin SJ, Kaplan L, Reid S, Parada LF, Kaplan DR (1992) Overexpression of the trk tyrosine kinase rapidly accelerates nerve growth factor-induced differentiation. Neuron 9:883-896.

Heymach Jr JV, Shooter EM (1995) The biosynthesis of neurotrophin heterodimers by transfected mammalian cells. J Biol Chem 270:12297-12304.

Heymach Jr JV, Kruttgen A, Suter U, Shooter EM (1996) The regulated secretion and vectorial targeting of neurotrophins in neuroendocrine and epithelial cells. J Biol Chem 271:25430-25437. 
Hibbert AP, Morris SJ, Seidah NG, Murphy RA (2003) Neurotrophin-4, alone or heterodimerized with brain-derived neurotrophic factor, is sorted to the constitutive secretory pathway. J Biol Chem 278:48129-48136.

Hiltunen JO, Arumae U, Moshnyakov M, Saarma M (1996) Expression of mRNAs for neurotrophins and their receptors in developing rat heart. Circ Res 79:930-939.

Huang E, Reichardt L (2001) Neurotrophins: roles in neuronal development and function. Annu Rev Neurosci 24:677-736.

Huttner WB, Gerdes HH, Rosa P (1991) The granin (chromogranin/secretogranin) family. Trends Biochem Sci 16:27-30.

Kang H, Schuman EM (1995) Long-lasting neurotrophin-induced enhancement of synaptic transmission in the adult hippocampus. Science 267:1658-1662.

Korte M, Carroll P, Wolf E, Brem G, Thoenen H, Bonhoeffer T (1995) Hippocampal long-term potentiation is impaired in mice lacking brainderived neurotrophic factor. Proc Natl Acad Sci USA 92:8856-8860.

Kraemer R, Nguyen H, March KL, Hempstead B (1999) NGF activates similar intracellular signaling pathways in vascular smooth muscle cells as PDGF-BB but elicits different biological responses. Arterioscler Thromb Vasc Biol 19:1041-1050.

Lee F, Chao M (2001) Activation of Trk neurotrophin receptors in the absence of neurotrophins. Proc Natl Acad Sci USA 92:3555-3560.

Lee R, Kermani P, Teng K, Hempstead B (2001) Regulation of cell survival by secreted proneurotrophins. Science 294:1945-1948.

Levine E, Dreyfus C, Black I, Plummer M (1996) Selective role for trkB neurotrophin receptors in rapid modulation of hippocampal synaptic transmission. Mol Brain Res 38:300-303.

Levine ES, Dreyfus CF, Black IB, Plummer MR (1995) Brain-derived neurotrophic factor rapidly enhances synaptic transmission in hippocampal neurons via postsynaptic tyrosine kinase receptors. Proc Natl Acad Sci USA 92:8074-8077.

Lu B (2003a) BDNF and activity-dependent synaptic modulation. Learn Mem 100:86-98.

Lu B (2003b) Pro-region of neurotrophins. Role in synaptic modulation. Neuron 39:735-738.

Momose Y, Murata M, Kobayashi K, Tachikawa M, Nakabayashi Y, Kanazawa I, Toda T (2002) Association studies of multiple candidate genes for Parkinson's disease using single nucleotide polymorphisms. Ann Neurol 51:133-136.

Mowla S, Pareek S, Farhadi H, Petrecca K, Fawcett J, Seidah N, Morris S, Sossin W, Murphy R (1999) Differential sorting of nerve growth factor and brain-derived neurotrophic factor in hippocampal neurons. J Neurosci 19:2069-2080.
Mowla S, Farhadi H, Pareek S, Atwal J, Morris S, Seidah N, Murphy R (2001) Biosynthesis and post-translational processing of the precursor to brainderived neurotrophic factor. J Biol Chem 276:12660-12666.

Neves-Pereira M, Mundo E, Muglia P, King N, Macciardi F, Kennedy J (2002) The brain-derived neurotrophic factor gene confers susceptibility to bipolar disorder: evidence from a family-based association study. Am J Hum Genet 71:651-655.

Ozawa H, Takata K (1995) The granin family—its role in sorting and secretory granule formation. Cell Struct Funct 20:415-420.

Poo M (2001) Neurotrophins as synaptic modulators. Nat Rev Neurosci 2:24-31.

Ribases M, Gratacos M, Armengol L, De Cid R, Badia A, Jimenez L, Solano R, Vallejo J, Fernandez F, Estivill X (2003) Met66 in the brain-derived neurotrophic factor (BDNF) precursor is associated with anorexia nervosa restrictive type. Mol Psychiatry 8:745-751.

Scarisbrick IA, Jones EG, Isackson PJ (1993) Coexpression of mRNAs for NGF, BDNF, and NT-3 in the cardiovascular system of the pre- and postnatal rat. J Neurosci 13:875-893.

Schubert D, Klier FG (1977) Storage and release of acetylcholine by a clonal cell line. Proc Natl Acad Sci USA 74:5184-5188.

Schweitzer K, Vicart P, Delouis C, Paulin D, Drager A, Langenhuijsen M, Weksler B (1997) Characterization of a newly established human bone marrow endothelial cell line: distinct adhesive properties for hematopoietic progenitors compared with human umbilical vein endothelial cells. Lab Invest 76:25-36.

Sen S, Nesse R, Stoltenberg S, Li S, Gleiberman L, Chakravarti A, Weder A, Burmeister M (2003) A BDNF coding variant is associated with the NEO personality inventory domain neuroticism, a risk factor for depression. Neuropsychopharmacology 28:397-401.

Sklar P, Gabriel S, McInnis M, Bennett P, Lim Y, Tsan G, Schaffner S, Kirov G, Jones I, Owen M, Craddock N, JR D, Lander E (2002) Family-based association study of 76 candidate genes in bipolar disorder: BDNF is a potential risk locus. Brain-derived neutrophic factor. Mol Psychiatry 7:579-593.

Tessarollo L (1998) Pleiotropic functions of neurotrophins in development. Cytokine Growth Factor Rev 9:125-137.

Ventriglia M, Bocchio Chiavetto L, Benussi L, Binetti G, Zanetti O, Riva MA, Gennarelli M (2002) Association between the BDNF 196 A/G polymorphism and sporadic Alzheimer's disease. Mol Psychiatry 7:136-137.

Wang S, Bray P, McCaffrey T, March K, Hempstead BL, Kraemer R (2000) p75(NTR) mediates neurotrophin-induced apoptosis of vascular smooth muscle cells. Am J Pathol 157:1247-1258. 